\title{
Numerical Simulation of the Effect of Three Active Particles on the Ignition Characteristics of n-Decane
}

\author{
Lin $\mathrm{YI}^{\mathrm{a}}$, Peng SONG ${ }^{\mathrm{a}, 1}$, Dequan LIU ${ }^{\mathrm{a}}$, Meiqi $\mathrm{WANG}^{\mathrm{b}}$, Lei $\mathrm{CHEN}^{\mathrm{b}}$ and Mingming \\ $\mathrm{HAN}^{\mathrm{a}}$ \\ ${ }^{a}$ School of Mechanical and Electrical Engineering, Dalian Minzu University, China \\ ${ }^{\mathrm{b}}$ Aerospace Engineering Institute, Shenyang Aerospace University, China
}

\begin{abstract}
The effects of $\mathrm{H}, \mathrm{OH}$ and $\mathrm{O} 3$ active particles on $\mathrm{n}$-decane skeleton mechanism are studied under the conditions of pressure range $0.1 \sim 1.0 \mathrm{MPa}$, temperature range $1000 \sim 1400 \mathrm{~K}$ and equivalent ratio range $0.5 \sim 2.0$. Through sensitivity analysis, find out the elementary reaction affected by the active particles, and calculate the influence of three kinds of active particles on the ignition characteristics of $n$-decane. The results show that under other conditions unchanged, the higher the concentration of active particles added, the shorter the n-decane/air ignition delay time, and the addition of active particles can extend the lean burn limit of $\mathrm{n}$-decane by $10 \%$. Under $0.1 \mathrm{MPa}$ and $1000 \mathrm{~K}$ ambient conditions, by adding $0.5 \% \mathrm{H}, 0.5 \% \mathrm{OH}$ and $0.5 \% \mathrm{O} 3$, the ignition delay time of the mixture is reduced by $67.4 \%, 60.7 \%$, and $16.6 \%$ respectively. With the increase of pressure and equivalent ratio, the effects of the three active particles tend to be consistent.
\end{abstract}

Keywords. Active particles, skeleton mechanism, ignition delay time, sensitivity

\section{Introduction}

In recent years, with the continuous development of technology, a series of significant advances have been made in the research of plasma applications [1-2]. Plasmas have attracted a great deal of attention from researchers because they contain a large number of active particles that accelerate the chemical reactions of fuels and enhance combustion [3-4]. However, due to the complexity of plasma chemical reactions and the diversity of active particles generated by ionization, there are few studies on the reaction mechanism of plasma-excited aviation kerosene combustion, and the construction of a high-precision reaction mechanism is a prerequisite for an accurate numerical simulation study. Therefore, it is necessary to study the reaction mechanism of plasma-assisted aviation kerosene combustion and to explore the key active particle types and their mechanisms in which plasma plays a dominant role in assisted combustion [5].

The Klimov group of the Institute of High Temperature Research of the Russian Academy of Sciences [6-8] conducted a lot of research work on supersonic plasma

${ }^{1}$ Corresponding Author, Peng SONG, School of Mechanical and Electrical Engineering, Dalian Minzu University, China; Email: 279972560@qq.com. 
combustion technology, and the tests showed that the plasma discharge can increase the premixed gas temperature, produce a large number of chemically active particles, improve the blending effect of fuel and fresh air, and enhance combustion stability.

Nagaraja[9] investigated the ignition characteristics of nanosecond pulsed dielectric blocked discharge plasma, which was the first attempt to use nanosecond pulsed discharge for the kinetic and thermal effects of two-stage ignition process of n-heptane. It was found that the active particles such as $\mathrm{OH}, \mathrm{H}$ and $\mathrm{O}$ generated at the beginning of discharge accelerated the dissociation of $\mathrm{H}$ atoms in the mixture, greatly increased the reaction temperature, and reduced the induction time of exothermic cycle by $90 \%$.

Xingjian Liu[10] studied the effect of plasma on the combustion characteristics of aviation kerosene under low equivalence ratio conditions. A circular tube type dielectric barrier discharge exciter was used for validation experiments and compared with the parameters without plasma addition. The experimental results show that the combustion efficiency increases and the poor quenching boundary expands when the power duty cycle or the working medium flow rate of the combustion aid exciter decreases and the discharge voltage increases, and the combustion performance is improved to some extent after the plasma combustion aid excitation is applied. $\mathrm{O}_{3}$ generated by plasma discharge is the main cause of plasma-excited aviation kerosene lean oil combustion. It is verified that plasma-excited combustion can improve the combustion performance of aviation kerosene poor oil.

In 2008, Lance et al. of the U.S. Air Force Research Laboratory[11] showed that a DC arc discharge plasma igniter consuming $2 \mathrm{KW}$ of power could produce a plasma jet with temperatures up to $5000 \mathrm{~K}$ and rich in reactive particles. And it was observed by PLIF that the concentration of active particle $\mathrm{OH}$ groups in the nucleus formed by plasma ignition of ethylene and JP-7 at an incoming Mach number of 2 and a total temperature of $590 \mathrm{~K}$ was greatly increased compared with that of normal spark plug ignition.

$\mathrm{The} \mathrm{Ju}$ research group at Princeton University[12-13] focused on microwave plasma-assisted combustion technology, and experiments showed that microwave plasma-assisted combustion of gaseous fuels can effectively broaden the extinction limit and increase the flame propagation speed to achieve the combustion of fuels under wide air pressure environment, wide temperature range, and extremely poor conditions.

In previous studies of plasma-enhanced ignition, most of the work has been done for standard atmospheric pressure conditions[14-15]. In real engine operation, a sudden drop in the velocity of the airflow occurs and the compressed air causes a pressure increase[16-17]. Therefore, it is necessary to study the mechanism related to the ignition of plasma-assisted aviation kerosene alternative fuel under high pressure conditions. In this study, the effect of the main active particles $\mathrm{H}, \mathrm{OH}$ and $\mathrm{O}_{3}$ in the discharge-excited generated plasma on the ignition delay of $\mathrm{C}_{10} \mathrm{H}_{22}$ /air with the chemical kinetic mechanisms involved is explored under high pressure and dilute conditions using a zero-dimensional, homogeneous, ignition model, respectively. 


\section{Research Method}

\subsection{Control Equations}

A zero-dimensional homogeneous ignition model is used as the basis for the development of a relevant ignition model. The effect of active particles in the plasma on the n-decane/air ignition process under adiabatic and constant pressure conditions is investigated. The energy equation is considered in the model to exclude the influence of factors such as transport (convection and diffusion) on the reaction process. The control equations are as follows[18].

Conservation of mass equation:

$$
\frac{d Y_{K}}{d t}=\frac{W_{K} \dot{\omega}_{K}}{\rho}
$$

Energy conservation equation:

$$
\frac{\mathrm{d} T}{d t}=-\frac{1}{\rho \bar{c}_{v}} \sum_{K=1}^{K} h_{K} W_{K} \dot{\omega}_{K}
$$

State equation:

$$
\rho=\frac{P \bar{W}}{R T}
$$

where, $Y_{k}, W_{k}, \omega_{k}$ and $h_{k}$ denote the mass fraction, mole mass, rate of generation and specific enthalpy of the k-th component; $\rho$ denotes density; $T$ denotes temperature; $\bar{c}_{v}$ denotes average constant volume specific heat; $P$ denotes pressure; $\bar{W}$ denotes average mole mass of the mixture; $R$ denotes gas constant; $t$ denotes time.

\subsection{Fire Delay Time}

In the high temperature case, the ignition delay time and the reaction parameters such as initial pressure, equivalence ratio, initial temperature, and oxidant concentration satisfy the Arrhenius form of the relationship [19], and equations (2.4) and (2.5) can be transformed into each other as follows:

$$
\begin{gathered}
\tau_{\text {ign }}=A\left[\mathrm{O}_{2}\right]^{\alpha}[\text { fuel }]^{\beta}[M]^{\gamma} \exp \left(\frac{E}{R T}\right) \\
\tau_{\text {ign }}=A P^{\alpha} \phi^{\beta} X_{\text {fuel }}^{\gamma} \exp \left(\frac{E}{R T}\right)
\end{gathered}
$$

Where, $A$ denotes the prefactor; $\left[O_{2}\right]$, [fuel $],[M]$ denote the concentration of oxidizer, fuel, and dilution gas, etc.; $\alpha, \beta, \gamma$ denote the influence factor of the corresponding parameter; $P$ denotes the initial pressure; $\phi$ denotes the equivalence ratio; $X_{\text {fuel }}$ denotes volume fraction of oxidant; $E$ denotes activation energy; $T$ denotes initial temperature; $R$ denotes gas universal constant, $R=8.314 \mathrm{~kJ} /(\mathrm{mol}-\mathrm{K})$.

Take the logarithm of equation (2.5) to get equation (2.6):

$$
\ln \tau_{\text {ign }}=\ln A+\alpha \ln P+\beta \ln \phi+\gamma \ln X_{f u e l}+\frac{E}{R T}
$$


It is obvious from equation (2.6) that the exponent of the ignition delay time of the fuel mixture is linearly related to the inverse of the temperature for equal pressure, same equivalence ratio and fuel concentration conditions.

\subsection{Model Building}

This paper selects the n-decane skeleton mechanism [20], establishes a chemical reaction kinetic model based on the existing combustion reaction mechanism, and adds $\mathrm{H}$ radicals, $\mathrm{OH}$ radicals, and $\mathrm{O}_{3}$ radicals on the basis of the $\mathrm{C}_{10} \mathrm{H}_{22} / \mathrm{O}_{2} / \mathrm{N}_{2}$ mixture. It is used to simulate the plasma-excited n-decane ignition process and form the plasma-excited n-decane combustion mechanism. Table 1 below shows the chemical reaction equations related to $\mathrm{O}_{3}$ [21-23].

Table 1. O3-related chemical reactions

\begin{tabular}{ccccc}
\hline \multirow{2}{*}{$\begin{array}{c}\text { Serial } \\
\text { number }\end{array}$} & Chemical reaction & \multicolumn{3}{c}{ Arrhenius Chemical Reaction Rate } \\
& & $\mathrm{A}\left(\mathrm{m}^{3} / \mathrm{s}\right)$ & $\mathrm{n}$ & $\mathrm{E}_{\mathrm{a}}(\mathrm{J} / \mathrm{mol})$ \\
\hline 1 & $\mathrm{O}_{2}+\mathrm{O}_{3}=>\mathrm{O}+\mathrm{O}_{2}+\mathrm{O}_{2}$ & $1.54 \mathrm{E}+14$ & 0 & 23064 \\
2 & $\mathrm{O}+\mathrm{O}_{2}+\mathrm{O}_{2}=>\mathrm{O}_{2}+\mathrm{O}_{3}$ & $3.26 \mathrm{E}+19$ & -2.1 & 0 \\
3 & $\mathrm{O}_{3}+\mathrm{N}_{2}=>\mathrm{O}+\mathrm{N}_{2}+\mathrm{O}_{2}$ & $4.00 \mathrm{E}+14$ & 0 & 22667 \\
4 & $\mathrm{O}_{2}+\mathrm{O}+\mathrm{N}_{2}=>\mathrm{O}_{3}+\mathrm{N}_{2}$ & $1.60 \mathrm{E}+14$ & -0.4 & -1391 \\
5 & $\mathrm{O}+\mathrm{O}_{3}=>\mathrm{O}+\mathrm{O}+\mathrm{O}_{2}$ & $2.48 \mathrm{E}+15$ & 0 & 22727 \\
6 & $\mathrm{O}_{2}+\mathrm{O}+\mathrm{O}=>\mathrm{O}_{3}+\mathrm{O}_{3}$ & $2.28 \mathrm{E}+15$ & -0.5 & -1391 \\
7 & $\mathrm{O}_{3}+\mathrm{O}_{3}=>\mathrm{O}+\mathrm{O}_{2}+\mathrm{O}_{3}$ & $4.40 \mathrm{E}+14$ & 0 & 23064 \\
8 & $\mathrm{O}+\mathrm{O} 2+\mathrm{O}_{3}=>\mathrm{O}_{3}+\mathrm{O}_{3}$ & $1.67 \mathrm{E}+15$ & -0.5 & -1391 \\
9 & $\mathrm{O}_{3}+\mathrm{H}<=>\mathrm{OH}^{2}+\mathrm{O}_{2}$ & $8.43 \mathrm{E}+13$ & 0 & 934 \\
10 & $\mathrm{O}_{3}+\mathrm{H}<=>\mathrm{O}^{2}+\mathrm{HO}_{2}$ & $4.52 \mathrm{E}+11$ & 0 & 0 \\
11 & $\mathrm{O}_{3}+\mathrm{OH}<=>\mathrm{O}_{2}+\mathrm{HO}_{2}$ & $1.85 \mathrm{E}+11$ & 0 & 831 \\
12 & $\mathrm{O}_{3}+\mathrm{H}_{2} \mathrm{O}<=>\mathrm{O}_{2}+\mathrm{H}_{2} \mathrm{O}_{2}$ & $6.62 \mathrm{E}+01$ & 0 & 0 \\
13 & $\mathrm{O}_{3}+\mathrm{HO} 2<=>\mathrm{OH}_{2}+\mathrm{O}_{2}+\mathrm{O}_{2}$ & $6.62 \mathrm{E}+09$ & 0 & 994 \\
14 & $\mathrm{O}_{3}+\mathrm{O}<=>\mathrm{O}_{2}+\mathrm{O}_{2}$ & $4.82 \mathrm{E}+12$ & 0 & 4094 \\
15 & $\mathrm{O}_{3}+\mathrm{NO}<=>\mathrm{O}_{2}+\mathrm{NO}_{2}$ & $8.43 \mathrm{E}+11$ & 0 & 2603 \\
16 & $\mathrm{O}_{3}+\mathrm{CH} 3<=>\mathrm{CH}_{3} \mathrm{O}+\mathrm{O}_{2}$ & $5.83 \mathrm{E}+10$ & 0 & 0 \\
\hline
\end{tabular}

\section{Simulation Results}

\subsection{Effect of Active Particles on n-Decane at Different Pressures}

\subsubsection{Ignition Delay Time}

The same concentrations of reactive particles $\mathrm{H}, \mathrm{OH}$ and $\mathrm{O}_{3}$ are added to the reactants as $\mathrm{C}_{10} \mathrm{H}_{22}$ /air mixture with the initial conditions of initial temperature $1000 \mathrm{~K}-1500 \mathrm{~K}$, initial pressure $0.1 \mathrm{MPa}, 0.5 \mathrm{MPa}, 1.0 \mathrm{MPa}$, equivalence ratio 1.0 , and the concentrations 
of $\mathrm{H}, \mathrm{OH}$ and $\mathrm{O}_{3}$ radicals are $0.5 \%$.

Figure 1 shows the trend of ignition delay time as a function of the inverse of temperature for different reactive particles stimulated combustion at chemically appropriate ratios. As shown in the figure, the logarithm of the ignition delay time follows a linear relationship with the inverse of the temperature for all mixtures. The derived equations can be found in Chapter 2, Section 2 of this paper.

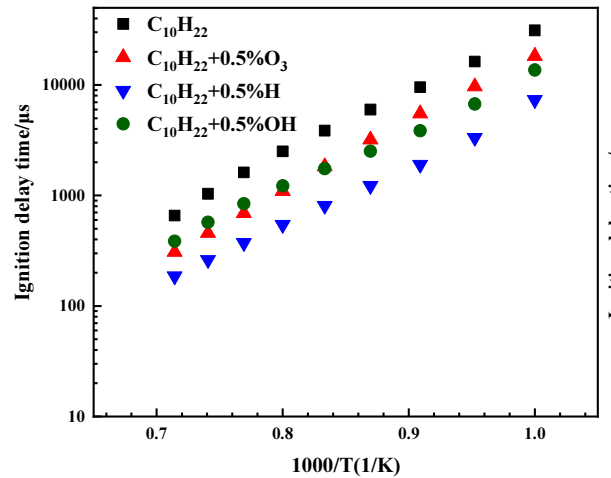

(a) $\mathrm{P}=0.1 \mathrm{MPa}$

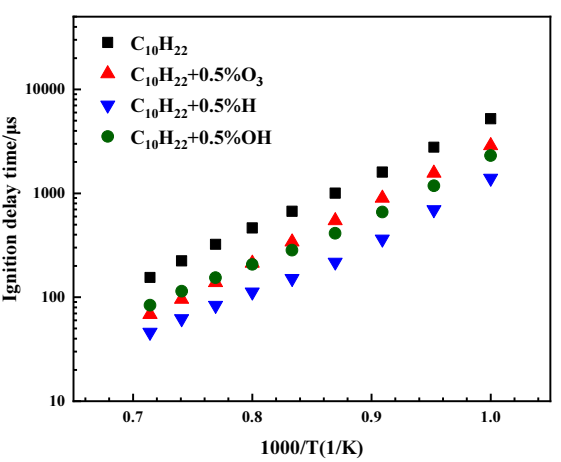

(b) $\mathrm{P}=0.5 \mathrm{MPa}$

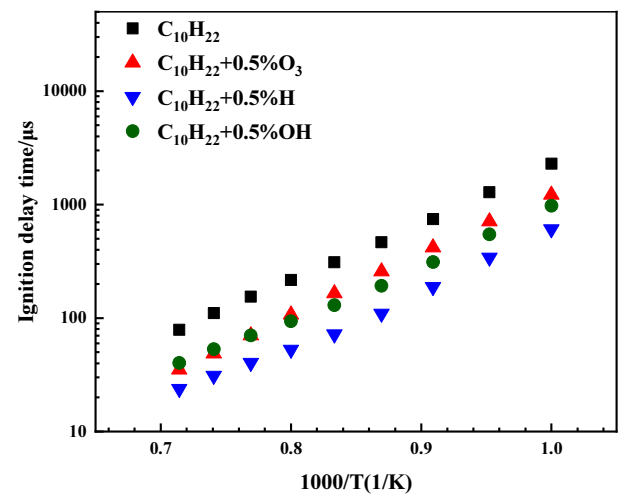

(c) $\mathrm{P}=1.0 \mathrm{MPa}$

Figure 1. Ignition delay times at pressures of $0.1,0.5$ and $1.0 \mathrm{MPa}$

As can be seen in figure 1 , the addition of $\mathrm{H}, \mathrm{OH}$, and $\mathrm{O}_{3}$ radicals, respectively, shortens the ignition delay time of the n-decane mixture when other conditions are the same. At $1000 \mathrm{~K}$, the shortest ignition delay time is obtained with the addition of $0.5 \% \mathrm{O}_{3}$, followed by the addition of $0.5 \% \mathrm{H}$ radicals. However, with the increase of temperature the ignition delay time after adding each of the three radicals is not much different, and the effect of the radicals is gradually weakening.

Comparing the three plots, it is found that the higher the pressure the shorter the ignition delay time for the same equivalence ratio and the same temperature. The number of molecules in the n-decane mixture increases as the pressure of the mixture increases. From a microscopic point of view, the molecular spacing is drastically reduced and the chance of ignition and combustion of n-decane in contact with oxidizer molecules increases. As a result, the increase in pressure leads to a shortening of the fuel ignition delay time. 


\subsubsection{Sensitivity Analysis}

In order to comprehensively analyze the effect of different initial conditions on the ignition delay time of $\mathrm{n}$-decane, this section investigates the temperature sensitivity analysis of the ignition delay time of the mixture under different initial pressures. From the perspective of reaction mechanism, it is analyzed that the ignition delay time of adding different active particles is affected by initial pressure, so as to obtain the main elementary reactions of the active particles affecting the ignition characteristics of n-decane under different initial pressures.

The initial temperature of $1000 \mathrm{~K}$, the equivalence ratio of 1.0 , and the initial pressures of $0.1 \mathrm{MPa}, 0.5 \mathrm{MPa}$, and $1.0 \mathrm{MPa}$ are chosen. First calculate the 20 elementary reactions with the largest sensitivity coefficient, and then select 4 elementary reactions with overlapping mechanisms for comparison. The results are shown in figure 2.

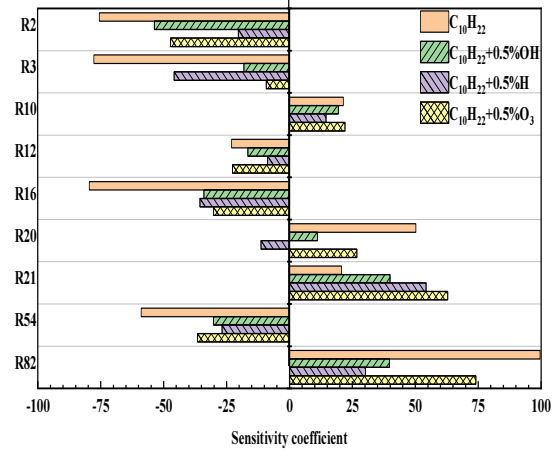

(a) $\mathrm{P}=0.1 \mathrm{MPa}$

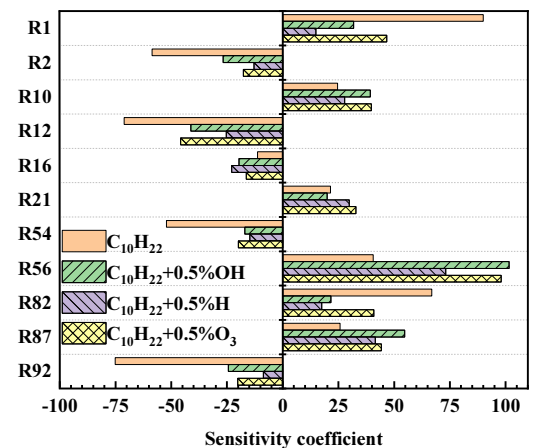

(b) $\mathrm{P}=0.5 \mathrm{MPa}$

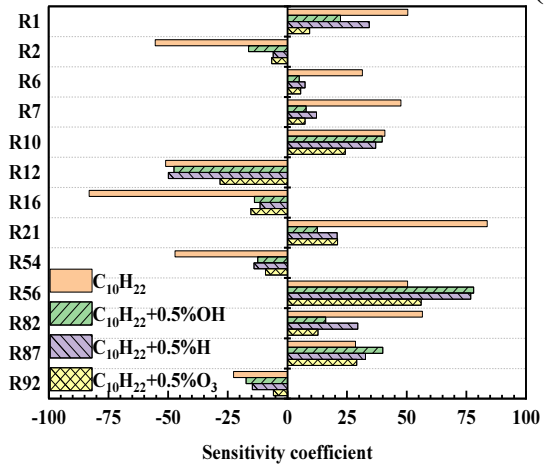

(c) $\mathrm{P}=1.0 \mathrm{MPa}$

Figure 2. Sensitivity analysis at pressures of $0.1,0.5$ and $1.0 \mathrm{MPa}$

From figure 2(a), it can be seen that most of the radical reactions increase in the direction of promoting the reaction after the addition of active particles.

$$
\begin{array}{r}
R 2: C_{10} H_{22}+O H \Leftrightarrow C_{10} H_{21}+H_{2} O \\
R 3: C_{10} H_{22}+H=>C_{10} H_{21}+H_{2} \\
R 12: C_{10} H_{21}=>2 C_{3} H_{6}+C_{2} H_{5}+C_{2} H_{4}
\end{array}
$$


The sensitivity coefficient of the above three reaction equations is less than 0 , inhibiting the increase of the reaction. The absolute value decreases with the addition of active particles, and the degree of inhibition of the reaction decreases. The sensitivity coefficient of $R 21$ is greater than 0 , which promotes the progress of the reaction. After the active particles are added, the sensitivity coefficient increases.

$$
\mathrm{R} 21: \mathrm{C}_{2} \mathrm{H}_{4}+\mathrm{OH}=\mathrm{CH} 2 \mathrm{O}+\mathrm{CH}_{3}
$$

It can be seen from the three plots that the sensitivity coefficients of most of the elementary reactions of the same mechanism decrease with the increase of pressure. It indicates that the pressure has a greater effect on the ignition delay time of the mixture, which affects the reaction rate of the elementary reactions.

\subsection{Effect of Active Particles on n-Decane at Different Equivalence Ratios}

\subsubsection{Gnition Delay Time}

In this section, the effect of active particles on the ignition delay time is studied for different equivalence ratios and other conditions. The initial conditions are pressure $0.5 \mathrm{MPa}$, temperature $1000-1500 \mathrm{~K}$, equivalent ratios $0.5,1.0$, and 2.0. Figure 3 shows the variation of the ignition delay time of the mixture with the initial temperature.

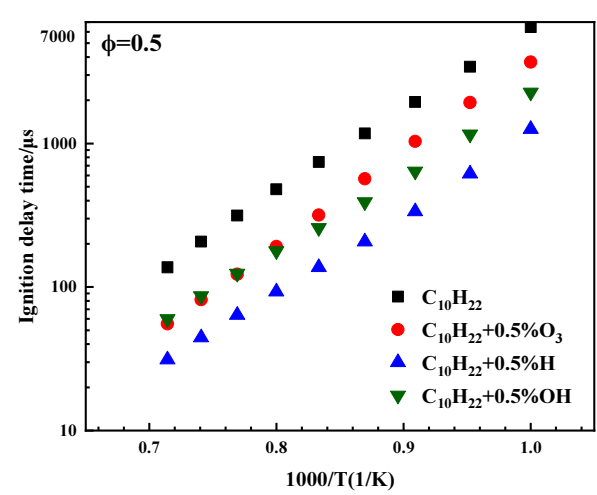

(a) $\phi=0.5$

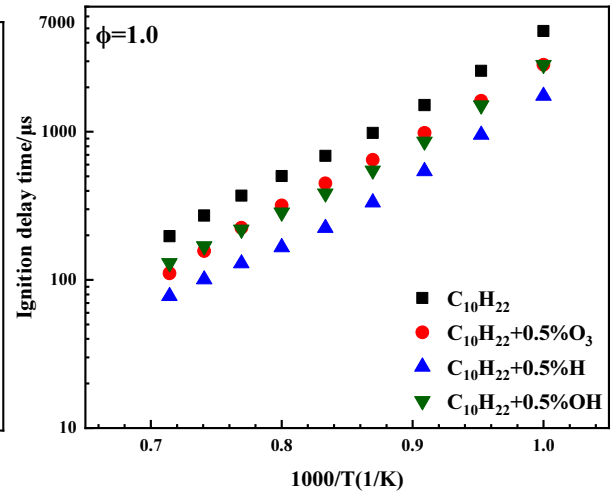

(b) $\phi=1.0$

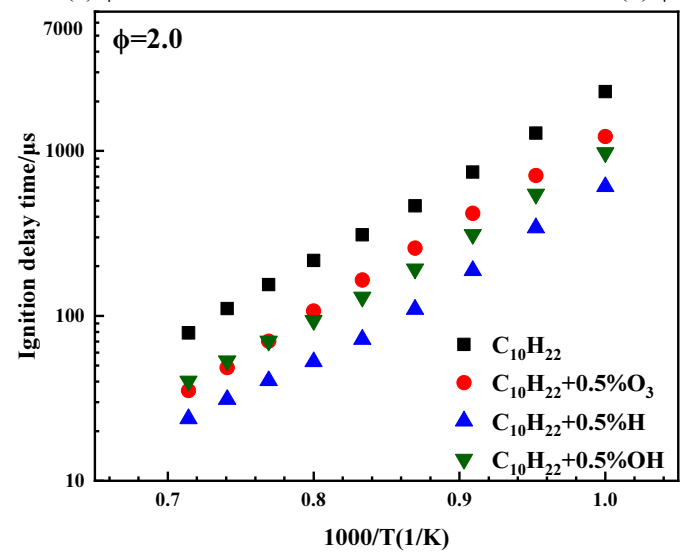

(c) $\phi=2.0$

Figure 3. Ignition delay times at equivalence ratios of $0.5,1.0$ and 2.0 
As shown in figure 3(a), when only the equivalent ratio is changed, the logarithm of the ignition delay time of the mixture has a linear relationship with the reciprocal of the ignition temperature. Under the same reaction conditions, the ignition delay time decreases with the addition of different active particles, but the ignition delay time decreases with a greater extent when adding $0.5 \% \mathrm{O}_{3}$ mixture, and the influence of $\mathrm{H}$ radical on the ignition delay time increases with the increase of temperature.

Comparing the three plots, it is found that the effect of the active particles tends to be consistent and is gradually weakening in the high temperature region as the temperature increases for the same equivalent ratio. The reason for this is that the activation energy of the mixture is higher in the high temperature region than in the low temperature region, and the effect of the active particles on n-decane gradually diminishes.

\subsubsection{Sensitivity Analysis}

In order to analyze the influence of mixture concentration on ignition delay time from the perspective of reaction mechanism, the temperature sensitivity analysis of ignition delay time of mixture is carried out to find out the main elementary reactions that affect the ignition characteristics of mixture under different equivalent ratios. The initial conditions are pressure $0.3 \mathrm{MPa}$, temperature $1000 \mathrm{~K}$, equivalent ratios $0.5,1.0$, and 2.0. The sensitivity coefficients of the most sensitive elementary reactions to ignition delay time are calculated under different equivalent ratios, and four elementary reactions with the same mechanism are selected.

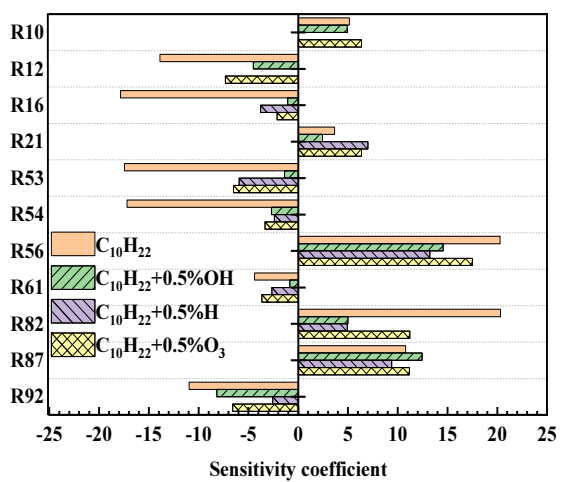

(a) $\phi=0.5$

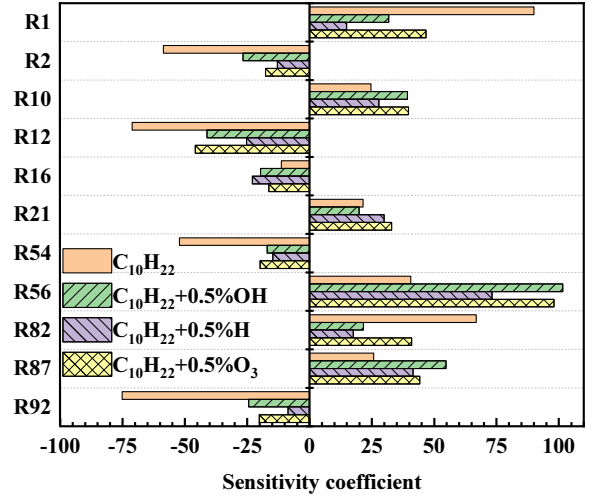

(b) $\phi=1.0$

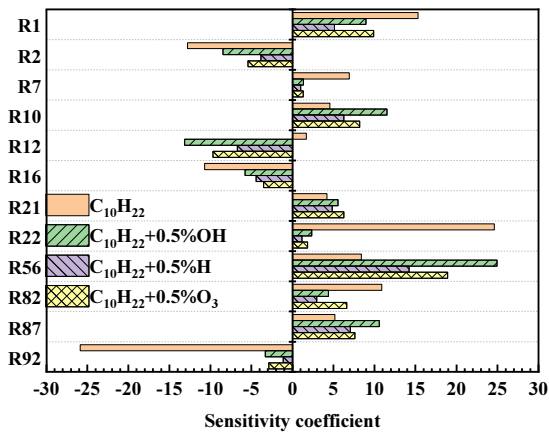

(c) $\phi=2.0$

Figure 4. Sensitivity analysis at equivalence ratios of $0.1,1.0$ and 2.0 
As can be seen from figure 4(a), the important reactions that affect the ignition delay time of the mixture vary considerably after the addition of active particles, especially for several reactions with the largest sensitivity coefficients, but most of the elementary reactions increase in the direction of promoting the reaction.

$$
\begin{aligned}
& R 12: \mathrm{C}_{10} \mathrm{H}_{21}=>2 \mathrm{C}_{3} \mathrm{H}_{6}+\mathrm{C}_{2} \mathrm{H}_{5}+\mathrm{C}_{2} \mathrm{H}_{4} \\
& R 16: \mathrm{C}_{3} \mathrm{H}_{6}+\mathrm{CH}_{3}=\mathrm{C}_{3} \mathrm{H}_{5}+\mathrm{CH}_{4} \\
& R 53: \mathrm{HO}_{2}+\mathrm{OH}=\mathrm{H}_{2} \mathrm{O}+\mathrm{O}_{2} \\
& R 61: \mathrm{H}_{2} \mathrm{O}_{2}+\mathrm{OH}=\mathrm{HO}_{2}+\mathrm{H}_{2} \mathrm{O} \\
& R 92: \mathrm{CH}_{3}+\mathrm{HO}_{2}=\mathrm{CH}_{4}+\mathrm{O}_{2}
\end{aligned}
$$

The temperature sensitivity coefficient is less than 0 , which inhibits the increase of the reaction. The absolute value decreases with the addition of active particles, and the degree of inhibition of the reaction decreases.

$$
\begin{aligned}
& R 21: \mathrm{C}_{2} \mathrm{H}_{4}+\mathrm{OH}=\mathrm{CH}_{2} \mathrm{O}+\mathrm{CH}_{3} \\
& \mathrm{R} 87: \mathrm{CH}_{3}+\mathrm{HO}_{2}=\mathrm{CH}_{3} \mathrm{O}+\mathrm{OH}
\end{aligned}
$$

The temperature sensitivity coefficient of $R 21$ and $R 87$ is less than 0 , which promotes the reaction, and the sensitivity coefficient increases with the addition of active particles.

\subsection{Expansion of the Dilute Combustion Limit}

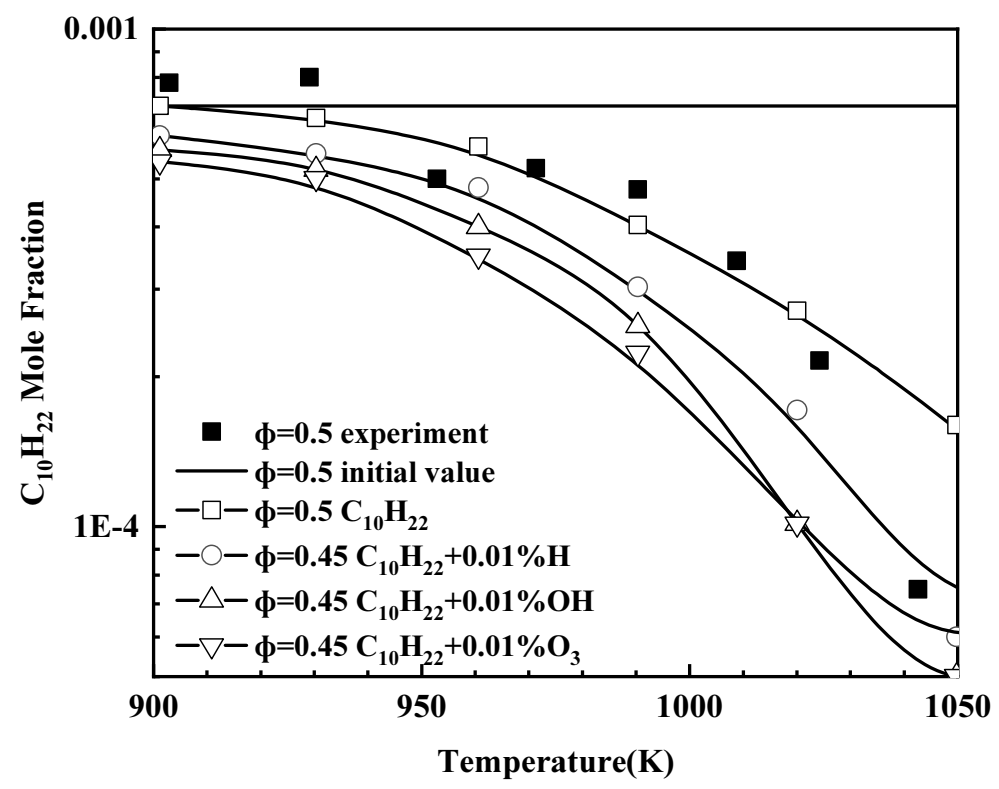

Figure 5. Variation of mole fraction of n-decane with temperature for different reaction components (symbols are experimental data of Dagaut et al. [24-25] and lines are simulation results for the same working conditions) 
Figure 5 shows the variation of the mole fraction of the main reactants n-decane at the end of the reaction with the initial temperature for $\mathrm{C}_{10} \mathrm{H}_{22} / \mathrm{O}_{2} / \mathrm{N}_{2}, \mathrm{C}_{10} \mathrm{H}_{22} / \mathrm{H} / \mathrm{O}_{2} / \mathrm{N}_{2}$, $\mathrm{C}_{10} \mathrm{H}_{22} / \mathrm{OH} / \mathrm{O}_{2} / \mathrm{N}_{2}$, and $\mathrm{C}_{10} \mathrm{H}_{22} / \mathrm{O}_{3} / \mathrm{O}_{2} / \mathrm{N}_{2}$ mixtures at different equivalence ratios. At the temperature of $900 \mathrm{~K}$ and equivalent ratio of 0.5 , the mole fraction of the $\mathrm{C}_{10} \mathrm{H}_{22} / \mathrm{O}_{2} / \mathrm{N}_{2}$ mixture does not change much from the initial set value, and no reaction occurs. After adding the active particles, the reaction can occur under the condition of an equivalent ratio of 0.45 .

According to the calculation results, after the addition of $\mathrm{OH}, \mathrm{O}_{3}$, and $\mathrm{H}$ three active particles, the lean burn limit of the $\mathrm{C} 10 \mathrm{H} 22 / \mathrm{O} 2 / \mathrm{N} 2$ mixture is reduced. This indicates that the addition of active particles has a significant effect on the expansion of the dilute ignition limit of n-decane fuel.

\section{Conclusion}

This paper studies the plasma combustion-supporting technology from the microscopic aspect, focusing on the effect of adding different active particles $\left(\mathrm{H}, \mathrm{OH}, \mathrm{O}_{3}\right)$ on the ignition characteristics of the n-decane framework mechanism. The effects of active particles on the ignition delay time under different working conditions are compared. Sensitivity analysis is used to study the effects of adding different active particles on elementary reactions, and to correct the mechanism with large errors. The main conclusions are as follows.

(1) Adding three kinds of active particles can shorten the ignition delay time. At $1000 \mathrm{~K}$, compared with the self-ignition of n-decane, the ignition delay is reduced by $67.4 \%$ with $0.5 \% \mathrm{H}, 60.7 \%$ with $0.5 \% \mathrm{OH}$, and $16.6 \%$ with $0.5 \% \mathrm{O}_{3}$.

(2) With the addition of reactive particles, the sensitivity coefficient of most of the elementary reactions increases in the direction of promoting the reaction, which enhances the influence on the ignition delay time of n-decane. Comparing the sensitivity coefficients of the three kinds of active particles, it was found that although some elementary reactions increased in the direction of inhibition, the overall reaction was promoted.

(3) Under the same conditions, the effects of three kinds of active particles on n-decane skeleton mechanism are compared. Among them, $\mathrm{H}$ radical has the most obvious stimulating effect, followed by $\mathrm{OH}$ radical, and finally $\mathrm{O}_{3}$ radical. The ignition delay time decreases with the increase of pressure and equivalent ratio. With the increase of temperature, the effect of free radicals gradually weakens, and the effect of the three active particles tends to be consistent.

(4) The addition of reactive particles reduces the concentration of reactants required for the reaction from 0.5 to 0.45 and extending the lean-burn limit by $10 \%$.

\section{Acknowledgments}

This study was supported by the China Aerodynamics Foundation (6141B090540), the Basic Research Project of Liaoning Provincial Education Department (JYT19059) and the National Natural Foundation of China (51676132). 


\section{Reference}

[1] Liu J-Z 2013 Reaction kinetics research of numerical simulation alternative fuel for aviation kerosene. D. Shenyang Aerospace University.

[2] Zhao J-X 2008 Pollutant emission and development of low-emission combustion technology for civil aero engine. J. Journal of Aerospace Power, 23(6): 986-996.

[3] Zeng W, Liu J, Zhang Z-B, et al. 2017 A new surrogate fuel of RP-3 kerosene. J. Journal of Aerospace Power, 32(10): 2314-2320.

[4] Liu Y, Zeng W, Ma H-A, et al. 2016 Effects of hydrogen addition on ignition characteristics of RP-3 kerosene. J. Journal of Propulsion Technology, 37(09): 1742-1751.

[5] He L-M, Liu X-J, Zhao B-B. 2016 Current investigation progress of plasma assisted ignition and combustion. J. Journal of Aerospace Power, 31(07): 1537-1551.

[6] Klimov A, Bityurin V, Brovkin V, et al. 2002 Optimization of plasma assisted combustion. C. Plasmadynamics \& Lasers Conference.

[7] Klimov A, Bityurin V, Kuznetsov A, et al. 2013 External and internal plasma-assisted combustion. C. 42nd AIAA Aerospace Sciences Meeting and Exhibit.

[8] Klimov A, Bitiurin V, Moralev I, et al. 2006 Non-premixed plasma-assisted combustion in high-speed airflow. C. 44th AIAA Aerospace Sciences Meeting and Exhibit.

[9] Nagaraja S, Sun W, Yang V. 2015 Effect of non-equilibrium plasma on two-stage ignition of n-heptane. J. Proceedings of the Combustion Institute, $\mathbf{3 5}$ : 3497-3504.

[10] Liu X-J, He L-M, Yang T, et al. 2016 Study on the effect of plasma fueling on the combustion of aviation kerosene lean oil. J. Propulsion Technology, 37(09): 1727-1734.

[11] Jacobsen L S, Carter C D, Baurle R A, et al. 2008 Toward plasma-assisted ignition in scramjets. J. Journal of Propulsion \& Power, 24(4):641-654.

[12] Ombrello T, Sang H-W, Ju Y, et al. 2013 Lifted Flame Speed Enhancement by Plasma Excitation of Oxygen. C. Aiaa Aerospace Sciences Meeting Including the New Horizons Forum \& Aerospace Exposition.

[13] Sun W-T, Uddi M, Ombrello T, et al. 2011 Effects of Non equilibrium plasma discharge on counterflow diffusion flame extinction. J. Proceedings of the Combustion Institute, 33 (2) : 3211-3218.

[14] Deepak G D, Joshi N K, Pal D K, et al. 2017 A low power miniaturized dielectric barrier discharge based atmospheric pressure plasma jet. J. Review of Scientific Instruments, 88(1): 013505.

[15] Shen S-Y, Jin X, Zhang P 2016 Analysis of the effect of reactive radicals on the delay time of kerosene cracking gas ignition. J. Propulsion Technology, 37(08): 1507-1514.

[16] Lou H-Q, Wei M-X, Liu R, et al. 2020 Experimental spray characteristics of self-pressurized nozzles for aero-piston engines. J. Journal of Aerodynamics, 35(12): 2583-2592.

[17] Liu A-G, Wang D, Yu H-Y, et al. 2020 Effect of fuel temperature on atomization performance of centrifugal nozzle. J. Journal of Aerodynamics, 35(09): 
1793-1800.

[18] You X, Egolfopoulos F N, Hai W 2009 Detailed and simplified kinetic models of n-dodecane oxidation: The role of fuel cracking in aliphatic hydrocarbon combustion. J. Proceedings of the Combustion Institute, 32(1): 403-410.

[19] Ma H-A 2016 Experimental and numerical study of the ignition and combustion characteristics of domestic RP-3 aviation kerosene. D. Dalian University of Technology.

[20] Chang Y, Jia M, Liu Y, et al. 2013 Development of a new skeletal mechanism for n-decane oxidation under engine-relevant conditions based on a decoupling methodology - ScienceDirect. J. Combustion and Flame, 160( 8):1315-1332.

[21] Wang Z-H, Yang L, Li B, et al. 2012 Investigation of combustion enhancement by ozone additive in $\mathrm{CH}_{4}$ /air flames using direct laminar burning velocity measurements and kinetic simulations. J. Combustion \& Flame, 159(1):120-129.

[22] F Halter, Higelin P, Dagaut P 2011 Experimental and detailed kinetic modeling study of the effect of ozone on the combustion of methane. J. Energy Fuels, 25(JUL.-AUG):2909-2916.

[23] Masurier J B, Foucher F, Dayma G, et al. 2014 Effect of additives on combustion characteristics of a natural gas fueled HCCI engine. C. Sae Powertrain, Fuel \& Lubricants.

[24] Dagaut P, Bakali A E, Ristori A 2006 The combustion of kerosene: Experimental results and kinetic modelling using 1- to 3-component surrogate model fuels. $J$. Fuel, 85(7-8):944-956.

[25] Dagaut P, Pengloan G, Ristori A 2002 Oxidation, ignition and combustion of toluene: Experimental and detailed chemical kinetic modeling. J. Physical Chemistry Chemical Physics. 